\title{
Influence of Pyrolysis Temperature and Pellet Size on Syngas Production from Sewage Sludge: towards Energy Recovery
}

\author{
Yuwen Zhu ${ }^{1,2, a *}$, Yanfang Miao ${ }^{1, b}$, Lei Zhang ${ }^{2,3, c}$ and Jiujun Yang ${ }^{2,3, d}$ \\ ${ }^{1}$ School of Energy and Safety Engineering, Tianjin Chengjian University, Tianjin, China \\ 2 Tianjin Key Laboratory of Soft Soil Characteristics and Engineering Environment, Tianjin, China \\ ${ }^{3}$ School of Materials Science and Engineering, Tianjin Chengjian University, Tianjin 300384, China \\ azhuyuwen4009@163.com, ${ }^{\text {b} 13488806524 @ 139 . c o m, ~}{ }^{c}$ zhanglei@tcu.edu.cn, \\ dyangjiujun@tcu.edu.cn
}

Keywords: Sewage sludge, Pyrolysis, Syngas, Pellet size, Operation mode

Abstract The energy recovery from sewage sludge has been turned out to be vital solution to the sludge problem. This study focused on the conversion of sewage sludge into syngas production. The effects of pyrolysis temperature and pellet size on syngas yield and composition were studied. The influence of operation mode on syngas yield was also investigated. Results showed that when the pyrolysis temperature increased from $450^{\circ} \mathrm{C}$ to $850^{\circ} \mathrm{C}$, the yield of syngas increased and the energy recovery of syngas reached maximum value of $5194.3 \mathrm{~J} \cdot \mathrm{g}^{-1}$. Besides, the maximum lower heating value (LHV) of syngas reached $31.5 \mathrm{MJ} \cdot \mathrm{m}^{-3}$ at $550{ }^{\circ} \mathrm{C}$ because the $\mathrm{CH}_{4}$ mole percentage in the total gas reached maximum value. The smaller pellet size was demonstrated to favour the production of $\mathrm{H}_{2}, \mathrm{CO}$ and $\mathrm{CH}_{4}$. The maximum $\mathrm{CO}$ and $\mathrm{H}_{2}$ yield can be achieved at pyrolysis temperature of $850^{\circ} \mathrm{C}$ for smaller particle size. The syngas yield obtained in continuous operation reactor was evidently lower than that in sequencing batch reactor at pyrolysis temperature of 450 and $550^{\circ} \mathrm{C}$. The difference of syngas yield in the two operation modes decreased with increasing pyrolysis temperature.

\section{Introduction}

The increase of sewage sludge production from municipal wastewater plants is a matter of growing concern. These sludges require proper treatments and disposals that are environmentally acceptable. Moreover, the cost of disposal of the bulk amount of sludge has increased greatly[1]. Conventional sewage sludge disposal methods, including using as soil conditioner in agriculture, landfills and ocean dumping, have shown lots of disadvantages because of energy waste and environmental problems[2,3].

In recent years, energy recovery from sewage sludge has been turned out to be vital solution to the sludge problem. There are several advantages over energy recovery from sewage sludge, including reducing volume of sewage sludge, turning a waste into a valuable energy source, and meeting the stringent environmental limitations on sewage sludge[1]. Energy recovery from sewage sludge can be achieved with combustion, gasification, wet oxidation and pyrolysis. Combustion and gasification processes release polychlorinated dibenzodioxins and furans leading to serious air pollution. However, the pyrolysis process is conducted in an anoxic atmosphere, thus the shortcomings of toxic gas release can be overcomed greatly[4,5]. In addition, it has been demonstrated that the heavy metals in sewage sludge can be solidified in the solid production (char)[6,7].

Many researchers have studied the effects of pyrolysis parameters on the yield and composition of the derived products from dried sewage sludge. In the literature, energy recovery from sewage sludge has been mostly focused on conversion of sewage sludge into bio-oil production as a high-energy feedstock[8]. But to the syngas production, which has advantages including reusing as clean fuels, easier to collect and transport, has been paid lower attention.

Therefore, the aim of this work focused on the maximisation of syngas from the pyrolysis conversion of sewage sludge, by optimizing the pyrolysis temperature and pellet size of raw material. The experiments were also performed respectively in a fixed bed reactor and in a continuous furnace, in order to investigate the influence of operation mode on syngas yield. 


\section{Material and methods}

Materials. The sewage sludge (SS) was supplied from Xianyang Road Municipal Wastewater Treatment Plant in Tianjin. Prior to use, the SS was air-dried for several days to remove the unbound moisture. Then the air-dried SS was sequentially dried in an oven for $12 \mathrm{~h}$ at $105 \pm 2{ }^{\circ} \mathrm{C}$. The dried SS was ground into small particles to make sample granularity arrive at 200 meshes. The powder SS was subsequently pelletized by manual operation to obtain two sizes of spherical stock. The smaller pellets were produced in sizes varying between 3 and $5 \mathrm{~mm}$ contrast to the bigger sizes varying between 9 and $11 \mathrm{~mm}$.

The proximate and ultimate analyses were taken place in a tube furnace and Vario MACRO CHNS element analyzer respectively according to GB483-87 in China as table 1 shown. The dried SS had a lower heating value (LHV) of $11.2 \mathrm{MJ} \cdot \mathrm{kg}^{-1}$.

Table 1 Analysis of raw material

\begin{tabular}{|c|c|c|c|c|c|c|c|c|c|}
\hline \multicolumn{5}{|c|}{ Proximate analysis [wt $\%$ ] } & \multicolumn{5}{|c|}{ Ultimate analysis [wt\%] } \\
\hline $\mathrm{M}$ & $\mathrm{V}$ & FC & $\mathrm{A}$ & $\mathrm{LHV} /\left(\mathrm{MJ} \cdot \mathrm{kg}^{-1}\right)$ & $\mathrm{C}$ & $\mathrm{H}$ & $\mathrm{O}^{*}$ & $\mathrm{~N}$ & $\mathrm{~S}$ \\
\hline 6.5 & 48.5 & 5.9 & 39.1 & 11.2 & 22.0 & 2.1 & 23.9 & 3.5 & 2.9 \\
\hline
\end{tabular}

Experimental apparatus and procedure. Some pyrolysis experiments were carried out in a fixed bed pyrolysis system with approximately $10 \mathrm{~g}$ samples used in each experiment. The pyrolysis system consisted of three parts: pyrolysis reactor, heater and condenser. The length of the quartz tube reactor with constant temperature was $400 \mathrm{~mm}$ and the inside diameter was $50 \mathrm{~mm}$. The each end of reactor were fixed and connected with flange which welded to a $6 \mathrm{~mm}$ pipe. The inlet was connected to a nitrogen cylinder and the outlet was connected to the ice bath condenser, respectively. Tar was eliminated by condensing (empty traps in ice bath), washing (traps with ethanol) and filter (silica gel filter).

Pyrolysis experiments were carried out in a nitrogen atmosphere prevailing in the pyrolysis reactor. The nitrogen was pumped into quartz tube reactor with $300 \mathrm{ml} \cdot \mathrm{min}^{-1}$ during the pyrolysis process. The reactor was heated at a rate of $10{ }^{\circ} \mathrm{C} / \mathrm{min}$, and when the required temperature was attained, the stock in a corundum crucible $(20 \mathrm{~cm} \times 4 \mathrm{~cm})$ was put into quartz tube reactor quickly. It was maintained until no pyrolysis gas was generated. The pyrolysis of SS samples was evaluated at various temperatures $\left(450,550,650,750\right.$ and $\left.850{ }^{\circ} \mathrm{C}\right)$. The gases produced from the pyrolysis were firstly passed through the ice bath condenser, the remaining gases were pumped into the gas analysis meter. The percentage contents of $\mathrm{H}_{2}, \mathrm{CO}, \mathrm{CO}_{2}, \mathrm{CH}_{4}$ and $\mathrm{C}_{\mathrm{n}} \mathrm{H}_{\mathrm{m}}$ can be real-time measured. The yields of gas produced were calculated by integration method.

Another part of pyrolysis experiments were carried out in a continuous operation reactor system. In this reactor system, the heater, condenser and measurement part were similar with the fixed bed pyrolysis system. The stock was continuous feed in the tube reactor by a screw feeder when the operating temperature remained stable at the set temperature. The predetermined pyrolysis time was implemented by controlling corresponding feed rate. A PPC trimmer was put under the outlet of the tube reactor to collect the solid production. The gases produced during the pyrolysis process were continuous pumped into condenser through another outlet. The non-condensable gases were pumped into the gas analysis meter to measure the percentage content of each gas produced.

\section{Results and discussion}

Influence of operating temperature. The SS particles between 0.25 and $0.38 \mathrm{~mm}$ were carried out at a rate of $8{ }^{\circ} \mathrm{C} / \mathrm{min}$ over a temperature range of $25-950{ }^{\circ} \mathrm{C}$ in nitrogen atmosphere. The pyrolysis gas compositions were obtained by gas analysis meter. It was indicated that these simple molecules which were responsible for the syngas formation were $\mathrm{CO}_{2}, \mathrm{H}_{2}, \mathrm{CO}$ and $\mathrm{CH}_{4}$. Based on the gases release curve obtained in our early work[9], it was decided to investigate pyrolysis of the SS over a temperature range of $450-850{ }^{\circ} \mathrm{C}$. 


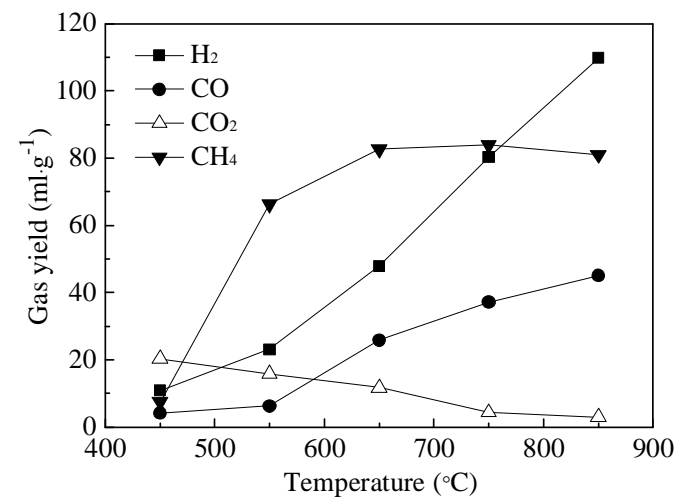

Fig. 1 Gas yields at different temperatures

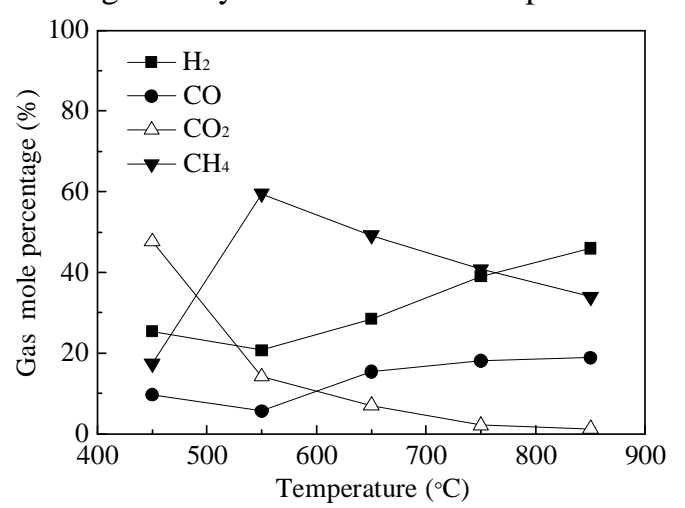

Fig.3 Gas mole percentage at different temperatures

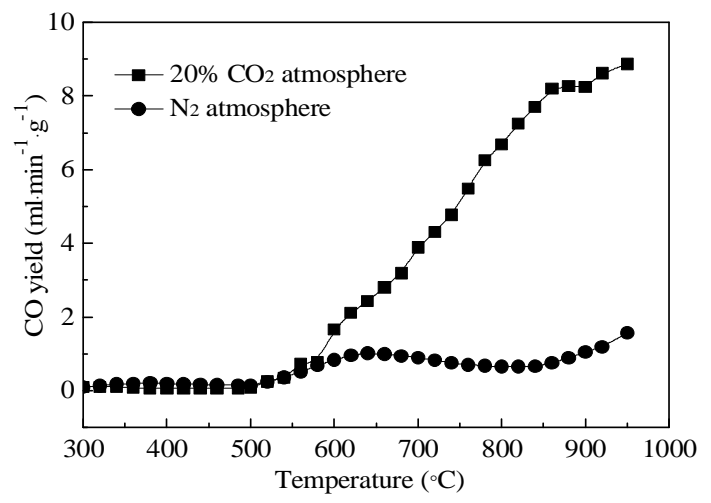

Fig. 2 Influence of $\mathrm{CO}_{2}$ atmosphere on $\mathrm{CO}$ yield

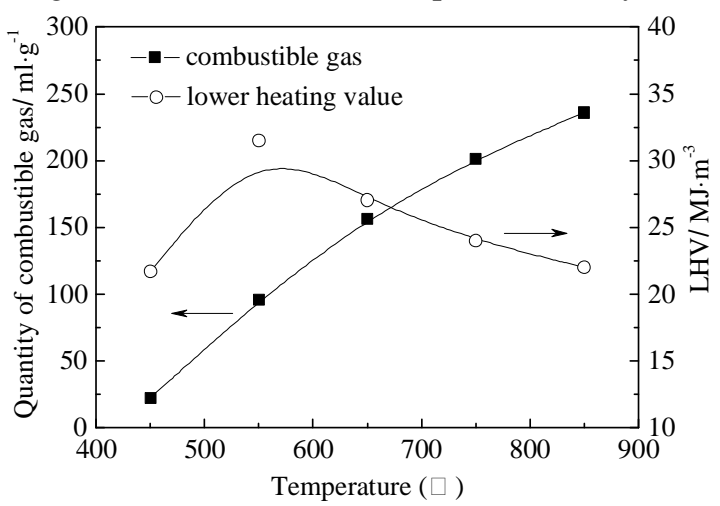

Fig.4 Quantity of combustible gas and LHV of syngas

From the results presented in Fig. 1, it can be seen that pyrolysis temperature had a marked influence on the gas yields. The $\mathrm{H}_{2}$ yield was found to improve proportionally with pyrolysis temperature. Maximum $\mathrm{H}_{2}$ yield reached $109.8 \mathrm{ml} \cdot \mathrm{g}^{-1}$ was obtained at $850^{\circ} \mathrm{C}$. Similar to the $\mathrm{H}_{2}$ yield, the temperature showed significant influence on $\mathrm{CO}$ production from pyrolysis of SS. The $\mathrm{CO}$ yield approximately reached half amount of pyrolyzed $\mathrm{H}_{2}$ at all temperatures investigated. The increased $\mathrm{CH}_{4}$ yield obtained with increasing the pyrolysis temperature from 450 to $650^{\circ} \mathrm{C}$. Moreover, it remained relatively constant at 650,750 and $850^{\circ} \mathrm{C}$. The $\mathrm{CO}_{2}$ production was significantly higher than the other gas when the pyrolysis temperature was at $450^{\circ} \mathrm{C}$, but the $\mathrm{CO}_{2}$ yield decreased with increasing the pyrolysis temperature. The significantly reduced yield of $\mathrm{CO}_{2}$ obtained at 750 and $850^{\circ} \mathrm{C}$. It was highly possible that $\mathrm{SS}$ provided $\mathrm{CO}_{2}$, promoting $\mathrm{CO}_{2}$-char gasification in the high pyrolysis temperature, which reduced the $\mathrm{CO}_{2}$ yield and benefited the increase of $\mathrm{CO}$ yield. The result could be explained by another contrast test. When $20 \% \mathrm{CO}_{2}$ existed in the pyrolysis atmosphere, the $\mathrm{CO}$ yield had a significant rise above $600^{\circ} \mathrm{C}$ as Fig. 2 shown. It was due to intense $\mathrm{CO}_{2}$-char gasification at high temperature, meanwhile, the original $\mathrm{CO}_{2}$ was consumed.

The conversion of energy from SS to the syngas production was illustrated in Fig. 4. The maximum conversion of combustible gas, including $\mathrm{H}_{2}, \mathrm{CO}, \mathrm{CH}_{4}$ and $\mathrm{C}_{\mathrm{n}} \mathrm{H}_{\mathrm{m}}$, was found to be $235.9 \mathrm{ml} \cdot \mathrm{g}^{-1}$ at 850 ${ }^{\circ} \mathrm{C}$. According to the lower heating value (LHV) and mole percentage of each combustible gas, the energy recovery of syngas reached maximum value of $5194.3 \mathrm{~J} \cdot \mathrm{g}^{-1}$. In contrast, the maximum LHV of syngas, reached $31.5 \mathrm{MJ} \cdot \mathrm{m}^{-3}$, obtained at $550{ }^{\circ} \mathrm{C}$, because the $\mathrm{CH}_{4}$ mole percentage in the total gas reached maximum value $(59.5 \%)$ as Fig. 3 shown.

Influence of pellet size. Trends in the syngas production at different operating temperatures for different pellet sizes were illustrated in Fig.5. $\mathrm{H}_{2}$ production from pyrolysis of $\mathrm{SS}$ at three different temperatures $\left(450,650\right.$ and $\left.850^{\circ} \mathrm{C}\right)$ and three pellet sizes $(0.25-0.38,3-5,9-11 \mathrm{~mm})$ were shown in Fig. 5(a). The $\mathrm{H}_{2}$ yield was found to decrease with increasing pellet size at all temperatures investigated. The reduced yields with pellet size could be due to inhibited heat transfer to the inner part of the particle. 

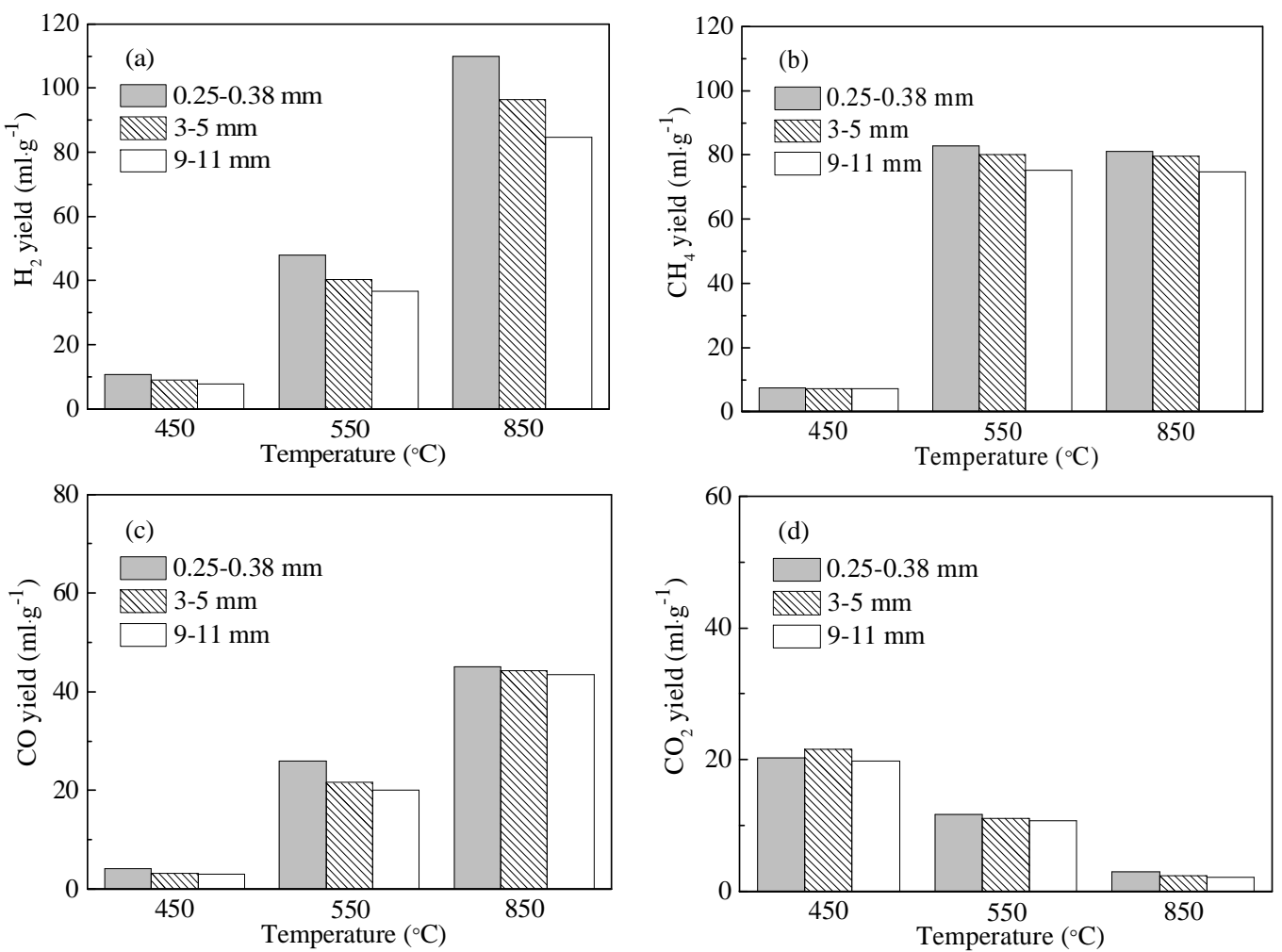

Fig.5 Pyrolysis gas yield for different pellets sizes

The influence of pellet size on $\mathrm{CH}_{4}$ yield was shown in Fig. 5(b). At pyrolysis temperature of $450^{\circ} \mathrm{C}$, the $\mathrm{CH}_{4}$ yield was mostly independent of pellet size, but there was a decrease with size at higher temperature. The influence of pellet size on $\mathrm{CO}$ yield was similar to that observed for $\mathrm{H}_{2}$ yield as Fig. 5(c) shown. The maximum $\mathrm{CO}$ yield can be achieved at high temperature for smaller particle size. The influence of pellet size on $\mathrm{CO}_{2}$ production was different with $\mathrm{H}_{2}$ and $\mathrm{CO}$ at $450^{\circ} \mathrm{C}$. At low temperature there was no complex secondary reaction occurred by the products[10], and $\mathrm{CO}_{2}$ originated from decomposition of carboxylic acid groups could be released completely during enough pyrolysis time. The $\mathrm{CO}_{2}$ yields were very low at pyrolysis temperature of $850{ }^{\circ} \mathrm{C}$ for all the three pellet sizes of SS as Fig. 5(d) shown.

Influence of operation mode. The quantity of syngas and solid products at different operating temperatures in sequencing batch reactor and continuous operation reactor were illustrated in Fig.6.
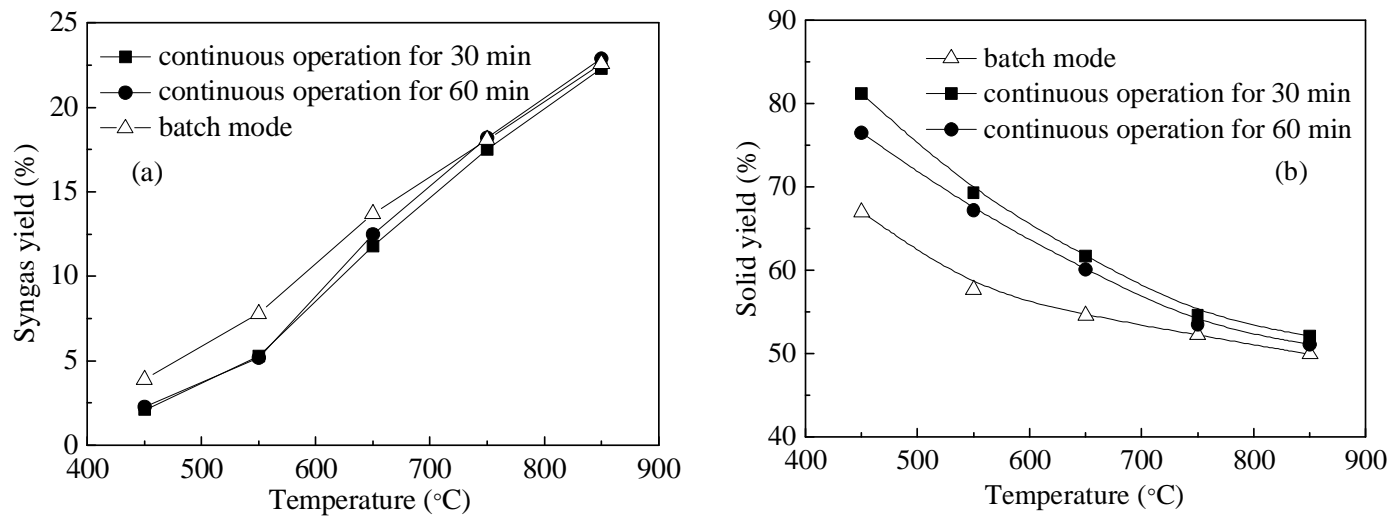

Fig.6 Comparison of pyrolysis gas yield and solid production for different operation modes

The total syngas yield was found to increase with increasing operating temperature either in sequencing batch reactor or continuous operation reactor as Fig 6 (a) shown. The syngas yield obtained in continuous mode was lower than that in sequencing batch mode at pyrolysis temperature of 450,550 and $650{ }^{\circ} \mathrm{C}$. The difference of syngas yield in the two operation modes decreased with increasing pyrolysis temperature. Moreover, the solid char yields in continuous operation reactor were evidently higher than that in sequencing batch reactor at lower operating temperature because of the solid char mixed with lots of tar. It is difficult to separate the tar from the solid production at 450, 550 
and $650{ }^{\circ} \mathrm{C}$ in continuous operation reactor. When the continuous reactor was operated at 750 and 850 ${ }^{\circ} \mathrm{C}$, the secondary reactions occurred completely and some macromolecules were decomposed to simple molecules released. It could be observed that the solid chars were dry and looked like the chars obtained in the sequencing batch reactor at high operating temperature.

\section{Conclusions}

The energy recovery from sewage sludge can be achieved with pyrolysis process. Operating temperature, pellet size and operation mode were found to have a significant influence on syngas composition and yield. The maximum $\mathrm{H}_{2}$ and $\mathrm{CO}$ yields can be achieved at high temperature $\left(850{ }^{\circ} \mathrm{C}\right)$ for smaller pellet size. The maximum conversion of combustible gas was found to be $235.9 \mathrm{ml}^{\circ} \mathrm{g}^{-1}$ at $850{ }^{\circ} \mathrm{C}$. Meanwhile, the energy recovery of syngas from SS pyrolysis reached maximum value of $5194.3 \mathrm{~J} \cdot \mathrm{g}^{-1}$. The operation mode had a significant effect on the yield of the pyrolysis syngas. The syngas yield obtained in continuous mode was evidently lower than that in sequencing batch mode at low pyrolysis temperatures.

\section{Acknowledgments}

Research was supported by the Tianjin Research Program of Application Foundation and Advanced Technology (13JCZDJC36300).

\section{References}

[1] C. Karaca, H.C. Okutan, S. Sozen, D. Orhon, Energy recovery with syngas production from sewage sludge using high rate pyrolysis at high temperature, Proceedings of SEEP2015. (2015) 11-14.

[2] H. Chen, D.Z. Chen, H. Liu, Influences of activation agent impregnated sewage sludge pyrolysis on emission characteristics of volatile combustion and De-NOx performance of activated char, Applied Energy.156 (2015) 767-775.

[3] A. J. Ridout, M. Carrier, J. Görgens, Fast pyrolysis of low and high ash paper waste sludge: Influence of reactor temperature and pellet size, Journal of Analytical \& Applied Pyrolysis. 111(2015) 64-75.

[4] W.Y. Xu, D. Wu, Comprehensive utilization of the pyrolysis products from sewage sludge, Environmental Technology. 36 (2015) 1731-1744.

[5] M. Agarwal, J. Tardio, and S.V. Mohan, Pyrolysis of activated sludge: Energy analysis and its technical feasibility, Bioresource Technology. 178 (2015) 70-75.

[6] P. Thipkhunthod, V. Meeyoo, P. Rangsunvigit, Pyrolytic characteristics of sewage sludge, Chemosphere. 64 (2006) 955-962.

[7] M.E. Sanchez, J.A. Menendez, A. Dominguez, Effect of pyrolysis temperature on the composition of the oils obtained from sewage sludge, Biomass \& Bioenergy. 33 (2009) 933-940.

[8] L. Shen, D.K. Zhang, An experimental study of oil recovery from sewage sludge by low-temperature pyrolysis in a fluidized-bed, Fuel. 82 (2003) 465-472.

[9] Y.W. Zhu, Y. Wang, L. Zhang, J.J. Yang, Change of products distributions and its recycled heat value during sludge pyrolysis, Journal of Anhui Agricultural. 43 (2015) 187-190.

[10] J.A. Caballero, R. Front, A. Marcilla, Characterization of sewage sludges by primary and secondary pyrolysis, Journal of Analytical and Applied Pyrolysis. 40 (1997) 433-450. 